\title{
An approximation method for common fixed points of a finite family of asymptotic pointwise nonexpansive mappings
}

\author{
Bancha Nanjaras ${ }^{1}$ and Bancha Panyanak ${ }^{1,2^{*}}$
}

\section{"Correspondence:}

banchap@chiangmai.ac.th

'Department of Mathematics,

Faculty of Science, Chaing Mai

University, Chiang Mai, 50200,

Thailand

${ }^{2}$ Centre of Excellence in

Mathematics, CHE, Si Ayutthaya Rd.

Bangkok, 10400, Thailand

\begin{abstract}
In this article, we consider an iterative scheme to approximate a common fixed point for a finite family of asymptotic pointwise nonexpansive mappings. We obtain weak and strong convergence theorems of the proposed iteration in uniformly convex Banach spaces. The related results for complete CAT(0) spaces are also included. MSC: $47 \mathrm{H} 09 ; 47 \mathrm{H} 10$
\end{abstract}

Keywords: common fixed point; asymptotic pointwise nonexpansive mapping; weak convergence; strong convergence; Banach space; CAT(0) space

\section{Introduction}

It is well known that many of the most important nonlinear problems of applied mathematics reduce to solving a given equation which in turn may be reduced to finding the fixed points of a certain operator. It is important not only to know the fixed points exist, but also to be able to construct that fixed points. Lau is a great mathematician who has published many good papers concerning to the existence and the approximation of fixed points for various types of mappings (see, e.g., [1-11]).

The existence of fixed points for nonexpansive mappings was studied independently by three authors in 1965 (see Browder [12], Göhde [13], and Kirk [14]). Since then the iteration methods for approximating fixed points of nonexpansive mappings has rapidly been developed and many of papers have appeared (see, e.g., [15-21]). One of the popular classes of generalized nonexpansive mappings is the class of asymptotically nonexpansive mappings which was introduced by Goebel and Kirk [22] in 1972. Later on, Kirk and Xu [23] introduced the concept of asymptotic pointwise nonexpansive mappings which generalizes the concept of asymptotically nonexpansive mappings and proved the existence of fixed points for such maps in a uniformly convex Banach space. In 2011, Kozlowski [24] defined an iterative sequence for an asymptotic pointwise nonexpansive mapping $T$ on a convex subset $C$ of a Banach space $X$ by $x_{1} \in C$ and

$$
\begin{aligned}
& x_{k+1}=\left(1-t_{k}\right) x_{k}+t_{k} T^{n_{k}} y_{k}, \\
& y_{k}=\left(1-s_{k}\right) x_{k}+s_{k} T^{n_{k}} x_{k}, \quad k \in \mathbb{N},
\end{aligned}
$$

where $\left\{t_{k}\right\}$ and $\left\{s_{k}\right\}$ are sequences in $[0,1]$ and $\left\{n_{k}\right\}$ is an increasing sequence of natural numbers. He proved, under some suitable assumptions, that the sequence $\left\{x_{k}\right\}$ defined by (1) converges weakly to a fixed point of $T$ where $X$ is a uniformly convex Banach space

C 2012 Nanjaras and Panyanak; licensee Springer. This is an Open Access article distributed under the terms of the Creative Commons Attribution License (http://creativecommons.org/licenses/by/2.0), which permits unrestricted use, distribution, and reproduction in any medium, provided the original work is properly cited. 
which satisfies the Opial condition and $\left\{x_{k}\right\}$ converges strongly to a fixed point of $T$ provided $T^{r}$ is a compact mapping for some $r \in \mathbb{N}$. Recently, Pasom and Panyanak [25] extended Kozlowski's results to a finite family of asymptotic pointwise nonexpansive mappings $T_{1}, \ldots, T_{m}$. Precisely, they proved weak and strong convergence theorems of the iterative process defined by

$$
\begin{aligned}
& x_{k+1}=\left(1-t_{m k}\right) x_{k}+t_{m k} T_{m}^{n_{k}} y_{(m-1) k}, \\
& y_{(m-1) k}=\left(1-t_{(m-1) k}\right) x_{k}+t_{(m-1) k} T_{m-1}^{n_{k}} y_{(m-2) k}, \\
& y_{(m-2) k}=\left(1-t_{(m-2) k}\right) x_{k}+t_{(m-2) k} T_{m-2}^{n_{k}} y_{(m-3) k}, \\
& \vdots \\
& y_{2 k}=\left(1-t_{2 k}\right) x_{k}+t_{2 k} T_{2}^{n_{k}} y_{1 k}, \\
& y_{1 k}=\left(1-t_{1 k}\right) x_{k}+t_{1 k} T_{1}^{n_{k}} y_{0 k}, \\
& y_{0 k}=x_{k}, \quad k \in \mathbb{N},
\end{aligned}
$$

where $\left\{t_{i k}\right\}_{k=1}^{\infty}$ are sequences in $[0,1]$ for all $i=1,2, \ldots, m$, and $\left\{n_{k}\right\}$ be an increasing sequence of natural numbers. On the other hand, Kettapun et al. [26] studied the iterative process defined by

$$
\begin{aligned}
& x_{k+1}=\left(1-t_{m k}\right) y_{(m-1) k}+t_{m k} T_{m}^{n} y_{(m-1) k}, \\
& y_{(m-1) k}=\left(1-t_{(m-1) k}\right) y_{(m-2) k}+t_{(m-1) k} T_{m-1}^{n} y_{(m-2) k}, \\
& y_{(m-2) k}=\left(1-t_{(m-2) k}\right) y_{(m-3) k}+t_{(m-2) k} T_{m-2}^{n} y_{(m-3) k}, \\
& \vdots \\
& y_{2 k}=\left(1-t_{2 k}\right) y_{1 k}+t_{2 k} T_{2}^{n} y_{1 k}, \\
& y_{1 k}=\left(1-t_{1 k}\right) y_{0 k}+t_{1 k} T_{1}^{n} y_{0 k}, \\
& y_{0 k}=x_{k}, \quad k \in \mathbb{N},
\end{aligned}
$$

where $T_{1}, \ldots, T_{m}$ are asymptotically quasi-nonexpansive mappings on $C$.

In this article, motivated by the results mentioned above, we obtain weak and strong convergence theorems of the iterative process defined by

$$
\begin{aligned}
& x_{k+1}=\left(1-t_{m k}\right) y_{(m-1) k}+t_{m k} T_{m}^{n_{k}} y_{(m-1) k}, \\
& y_{(m-1) k}=\left(1-t_{(m-1) k}\right) y_{(m-2) k}+t_{(m-1) k} T_{m-1}^{n_{k}} y_{(m-2) k}, \\
& y_{(m-2) k}=\left(1-t_{(m-2) k}\right) y_{(m-3) k}+t_{(m-2) k} T_{m-2}^{n_{k}} y_{(m-3) k}, \\
& \vdots \\
& y_{2 k}=\left(1-t_{2 k}\right) y_{1 k}+t_{2 k} T_{2}^{n_{k}} y_{1 k}, \\
& y_{1 k}=\left(1-t_{1 k}\right) y_{0 k}+t_{1 k} T_{1}^{n_{k}} y_{0 k}, \\
& y_{0 k}=x_{k}, \quad k \in \mathbb{N},
\end{aligned}
$$

where $T_{1}, \ldots, T_{m}$ are asymptotic pointwise nonexpansive mappings on $C,\left\{t_{i k}\right\}_{k=1}^{\infty}$ are sequences in $[0,1]$ for all $i=1,2, \ldots, m$, and $\left\{n_{k}\right\}$ be an increasing sequence of natural numbers.

\section{Preliminaries and lemmas}

Let $C$ be a nonempty subset of a metric space $(X, d)$ and $T$ be a mapping on $C$. A point $x$ in $C$ is called a fixed point of $T$ if $x=T x$. We shall denote by $F(T)$ the set of fixed points of $T$. The mapping $T: C \rightarrow C$ is said to be 
(i) nonexpansive if $d(T x, T y) \leq(x, y)$ for all $x, y \in C$,

(ii) asymptotically nonexpansive if there is a sequence $\left\{k_{n}\right\}$ of positive numbers with the property $\lim _{n \rightarrow \infty} k_{n}=1$ and such that

$$
d\left(T^{n} x, T^{n} y\right) \leq k_{n} d(x, y), \quad \text { for all } x, y \in C \text { and } n \geq 1,
$$

(iii) asymptotically quasi-nonexpansive if there is a sequence $\left\{k_{n}\right\}$ of positive numbers with the property $\lim _{n \rightarrow \infty} k_{n}=1$ and such that

$$
d\left(T^{n} x, p\right) \leq k_{n} d(x, p), \quad \text { for all } x \in C, p \in F(T) \text { and } n \geq 1,
$$

(iv) asymptotic pointwise nonexpansive if there exists a sequence of functions $\alpha_{n}: C \rightarrow[0, \infty)$ such that $\limsup _{n \rightarrow \infty} \alpha_{n}(x) \leq 1$ and

$$
d\left(T^{n} x, T^{n} y\right) \leq \alpha_{n}(x) d(x, y), \quad \text { for all } x, y \in C \text { and } n \geq 1 .
$$

The following implications hold.

$T$ is nonexpansive $\Rightarrow T$ is asymptotically nonexpansive $\Rightarrow T$ is asymptotically quasi-nonexpansive

$T$ is asymptotic pointwise nonexpansive

The existence of fixed points for asymptotic pointwise nonexpansive mappings in uniformly convex Banach spaces was proved by Kirk and $\mathrm{Xu}$ [23] as the following result.

Theorem 2.1 Let $C$ be a nonempty bounded closed and convex subset of a uniformly convex Banach space $X$. Then every asymptotic pointwise nonexpansive mapping $T: C \rightarrow C$ has a fixed point. Moreover, $F(T)$ is closed and convex.

For common fixed points of a family of commuting mappings, Pasom and Panyanak [27] obtained the following result.

Theorem 2.2 Let $C$ be a nonempty bounded closed convex subset of a uniformly convex Banach space $X$. Then every commuting family $\mathcal{S}$ of asymptotic pointwise nonexpansive mappings on $C$ has a nonempty closed convex common fixed point set.

Let $C$ be a nonempty subset of a metric space $(X, d)$. We shall denote by $\mathcal{T}(C)$ the class of all asymptotic pointwise nonexpansive mappings from $C$ into $C$. Let $T_{1}, \ldots, T_{m} \in \mathcal{T}(C)$, without loss of generality, we can assume that there exists a sequence of mappings $\alpha_{n}$ : $C \rightarrow[0, \infty)$ such that for all $x, y \in C, i=1, \ldots, m$, and $n \in \mathbb{N}$,

$$
d\left(T_{i}^{n} x, T_{i}^{n} y\right) \leq \alpha_{n}(x) d(x, y) \quad \text { and } \quad \limsup _{n \rightarrow \infty} \alpha_{n}(x) \leq 1 .
$$

Let $a_{n}(x)=\max \left\{\alpha_{n}(x), 1\right\}$. Again, without loss of generality, we can assume that

$$
d\left(T_{i}^{n} x, T_{i}^{n} y\right) \leq a_{n}(x) d(x, y), \quad \lim _{n \rightarrow \infty} a_{n}(x)=1 \quad \text { and } \quad a_{n}(x) \geq 1,
$$

for all $x, y \in C, i=1, \ldots, m$, and $n \in \mathbb{N}$. We define $b_{n}(x)=a_{n}(x)-1$, then for each $x \in C$ we have $\lim _{n \rightarrow \infty} b_{n}(x)=0$.

Definition 2.3 [24] Define $\mathcal{T}_{r}(C)$ as a class of all $T \in \mathcal{T}(C)$ such that

$\sum_{n=1}^{\infty} b_{n}(x)<\infty$ for every $x \in C$, and

$a_{n}$ is a bounded function for every $n \in \mathbb{N}$. 
Let $C$ be a nonempty subset of a Banach space $X$ and $T_{1}, \ldots, T_{m} \in \mathcal{T}_{r}(C)$. Let $\left\{t_{i k}\right\}_{k=1}^{\infty} \subset$ $(0,1)$ be bounded away from 0 and 1 for all $i=1,2, \ldots, m$ and $\left\{n_{k}\right\}$ be an increasing sequence of natural numbers. Let $x_{1} \in C$ and define a sequence $\left\{x_{k}\right\}$ in $C$ as

$$
\begin{aligned}
& x_{k+1}=\left(1-t_{m k}\right) y_{(m-1) k}+t_{m k} T_{m}^{n_{k}} y_{(m-1) k}, \\
& y_{(m-1) k}=\left(1-t_{(m-1) k}\right) y_{(m-2) k}+t_{(m-1) k} T_{m-1}^{n_{k}} y_{(m-2) k}, \\
& y_{(m-2) k}=\left(1-t_{(m-2) k}\right) y_{(m-3) k}+t_{(m-2) k} T_{m-2}^{n_{k}} y_{(m-3) k}, \\
& \vdots \\
& y_{2 k}=\left(1-t_{2 k}\right) y_{1 k}+t_{2 k} T_{2}^{n_{k}} y_{1 k}, \\
& y_{1 k}=\left(1-t_{1 k}\right) y_{0 k}+t_{1 k} T_{1}^{n_{k}} y_{0 k}, \\
& y_{0 k}=x_{k}, \quad k \in \mathbb{N} .
\end{aligned}
$$

We say that the sequence $\left\{x_{k}\right\}$ in (9) is well defined if $\limsup _{k \rightarrow \infty} a_{n_{k}}\left(x_{k}\right)=1$. As in [24], we observe that $\lim _{k \rightarrow \infty} a_{k}(x)=1$ for every $x \in C$. Hence, we can always choose a subsequence $\left\{a_{n_{k}}\right\}$ which makes $\left\{x_{k}\right\}$ well defined.

Definition 2.4 A strictly increasing sequence $\left\{n_{k}\right\} \subset \mathbb{N}$ is called quasi-periodic if the sequence $\left\{n_{k+1}-n_{k}\right\}$ is bounded, or equivalently if there exists a number $p \in \mathbb{N}$ such that any block of $p$ consecutive natural numbers must contain a term of the sequence $\left\{n_{k}\right\}$. The smallest of such numbers $p$ will be called a quasi-period of $\left\{n_{k}\right\}$.

Recall that a mapping $T: C \rightarrow C$ is called semi-compact if for any sequence $\left\{x_{n}\right\}$ in $C$ such that

$$
\lim _{n \rightarrow \infty} d\left(x_{n}, T x_{n}\right)=0,
$$

there exists a subsequence $\left\{x_{n_{j}}\right\}$ of $\left\{x_{n}\right\}$ and $q \in C$ such that $\lim _{j \rightarrow \infty} x_{n_{j}}=q$. A family of mapping $\left\{T_{i}: i=1,2, \ldots, m\right\}$ on $C$ is said to satisfy Condition $\left(A^{\prime \prime}\right)$ if there exists a nondecreasing function $f:[0, \infty) \rightarrow[0, \infty)$ with $f(0)=0$ and $f(r)>0$ for all $r>0$ such that $d\left(x, T_{j} x\right) \geq f(\operatorname{dist}(x, F))$, for some $j=1, \ldots, m$ for all $x \in C$, where $\operatorname{dist}(x, F)=\inf \{d(x, p): p \in$ $\left.F=\bigcap_{i=1}^{m} F\left(T_{i}\right)\right\}$.

Lemma 2.5 [28, Lemma 2.2] Let $\left\{s_{n}\right\}$ and $\left\{u_{n}\right\}$ be sequences of nonnegative real numbers satisfy:

$$
s_{n+1} \leq\left(1+u_{n}\right) s_{n}, \quad \text { for all } n \in \mathbb{N} \text {, and } \sum_{n=1}^{\infty} u_{n}<\infty .
$$

Then (i) $\lim _{n} s_{n}$ exists (ii) if $\liminf _{n} s_{n}=0$, then $\lim _{n} s_{n}=0$.

Lemma 2.6 [29, Lemma 1] Suppose $\left\{r_{k}\right\}$ is a bounded sequence of real numbers and $\left\{d_{k, l}\right\}$ is a doubly index sequence of real numbers which satisfy

$$
\limsup _{k \rightarrow \infty} \limsup _{l \rightarrow \infty} d_{k, l} \leq 0, \quad \text { and } \quad r_{k+l} \leq r_{k}+d_{k, l}
$$

for each $k, l \in \mathbb{N}$. Then $\lim _{k \rightarrow \infty} r_{k}=a$ for some $a \in \mathbb{R}$.

Lemma 2.7 [30,31] Let $X$ be a uniformly convex Banach space and let $\left\{t_{n}\right\}$ be a sequence in $[a, b]$ for some $a, b \in(0,1)$. Suppose that $\left\{u_{n}\right\}$ and $\left\{v_{n}\right\}$ are sequences in $X$ such that

$$
\limsup _{n \rightarrow \infty}\left\|u_{n}\right\| \leq r, \quad \limsup _{n \rightarrow \infty}\left\|v_{n}\right\| \leq r, \quad \text { and } \quad \lim _{n \rightarrow \infty}\left\|t_{n} u_{n}+\left(1-t_{n}\right) v_{n}\right\|=r,
$$

for some $r \geq 0$. Then $\lim _{n \rightarrow \infty}\left\|u_{n}-v_{n}\right\|=0$. 
Lemma 2.8 [24, Lemma 3.1] Let $C$ be a nonempty closed convex subset of a uniformly convex Banach space $X$ and let $T \in \mathcal{T}_{r}(C)$. If $\lim _{n \rightarrow \infty}\left\|x_{n}-T x_{n}\right\|=0$ then for any $m \in \mathbb{N}$, $\lim _{n \rightarrow \infty}\left\|x_{n}-T^{m} x_{n}\right\|=0$.

Lemma 2.9 [24, Theorem 3.1] Let $X$ be a uniformly convex Banach space with the Opial property and let $C$ be a nonempty closed convex subset of $X$. Let $T \in \mathcal{T}_{r}(C)$ and let $\omega \in X,\left\{x_{n}\right\} \subset X$ be such that weak $-\lim _{n \rightarrow \infty} x_{n}=\omega$ and $\lim _{n \rightarrow \infty}\left\|x_{n}-T x_{n}\right\|=0$. Then $\omega \in F(T)$.

\section{Results in Banach spaces}

\subsection{Results for bounded domains}

Recall that a subset $C$ of a metric space $(X, d)$ is said to be bounded if

$$
\operatorname{diam}(C):=\sup \{d(x, y): x, y \in C\}<\infty .
$$

Lemma 3.1 Let $C$ be a nonempty closed convex subset of a Banach space $X$ and $T_{1}, \ldots, T_{m} \in$ $\mathcal{T}_{r}(C)$. Let $\left\{t_{i k}\right\}_{k=1}^{\infty} \subset[0,1]$ and $\left\{n_{k}\right\} \subset \mathbb{N}$ be such that $\left\{x_{k}\right\}$ in (9) is well defined. Assume that $F:=\bigcap_{i=1}^{m} F\left(T_{i}\right) \neq \emptyset$. Then for each $p \in F$, there are sequences of nonnegative real numbers $\left\{\gamma_{k}\right\}$ and $\left\{\delta_{k}\right\}$ (depending on $p$ ) such that $\sum_{k=1}^{\infty} \gamma_{k}<\infty, \sum_{k=1}^{\infty} \delta_{k}<\infty$ and the following statements hold:

(i) $\left\|T_{i}^{n_{k}} y_{(i-1) k}-p\right\| \leq\left(1+\gamma_{k}\right)\left\|y_{(i-1) k}-p\right\|$, for all $i=1, \ldots, m$;

(ii) $\left\|y_{i k}-p\right\| \leq\left(1+\gamma_{k}\right)^{i}\left\|x_{k}-p\right\|$, for all $i=1, \ldots, m-1$;

(iii) $\left\|x_{k+1}-p\right\| \leq\left(1+\delta_{k}\right)\left\|x_{k}-p\right\|$;

(iv) if $C$ is bounded, then $\lim _{k \rightarrow \infty}\left\|x_{k}-p\right\|$ exists.

Proof Let $p \in F$ and $\gamma_{k}=b_{n_{k}}(p)$ for all $k \in \mathbb{N}$. Then $\sum_{k=1}^{\infty} \gamma_{k}<\infty$.

(i) For $i=1,2, \ldots, m$, we have

$$
\left\|T_{i}^{n_{k}} y_{(i-1) k}-p\right\| \leq\left(1+\gamma_{k}\right)\left\|y_{(i-1) k}-p\right\| .
$$

(ii) By (9), we obtain

$$
\begin{aligned}
\left\|y_{1 k}-p\right\| & =\left\|\left(1-t_{1 k}\right)\left(x_{k}-p\right)+t_{1 k}\left(T_{1}^{n_{k}} x_{k}-p\right)\right\| \\
& \leq\left(1-t_{1 k}\right)\left\|x_{k}-p\right\|+t_{1 k}\left\|T_{1}^{n_{k}} x_{k}-p\right\| \\
& \leq\left(1-t_{1 k}\right)\left\|x_{k}-p\right\|+t_{1 k}\left(1+\gamma_{k}\right)\left\|x_{k}-p\right\| \\
& \leq\left(1+\gamma_{k}\right)\left\|x_{k}-p\right\| .
\end{aligned}
$$

We assume that $\left\|y_{j k}-p\right\| \leq\left(1+\gamma_{k}\right)^{j}\left\|x_{k}-p\right\|$ holds for some $j=1, \ldots, m-2$. From part (i), we have

$$
\begin{aligned}
\left\|y_{(j+1) k}-p\right\| & =\left\|\left(1-t_{(j+1) k}\right)\left(y_{j k}-p\right)+t_{(j+1) k}\left(T_{j+1}^{n_{k}} y_{j k}-p\right)\right\| \\
& \leq\left(1-t_{(j+1) k}\right)\left\|y_{j k}-p\right\|+t_{(j+1) k}\left\|T_{j+1}^{n_{k}} y_{j k}-p\right\| \\
& \leq\left(1-t_{(j+1) k}\right)\left\|y_{j k}-p\right\|+t_{(j+1) k}\left(1+\gamma_{k}\right)\left\|y_{j k}-p\right\| \\
& \leq\left(1+\gamma_{k}\right)\left\|y_{j k}-p\right\| \\
& \leq\left(1+\gamma_{k}\right)\left(1+\gamma_{k}\right)^{j}\left\|x_{k}-p\right\| \\
& =\left(1+\gamma_{k}\right)^{j+1}\left\|x_{k}-p\right\| .
\end{aligned}
$$

By mathematical induction, we obtain

$$
\left\|y_{i k}-p\right\| \leq\left(1+\gamma_{k}\right)^{i}\left\|x_{k}-p\right\|, \quad \text { for all } i=1, \ldots, m-1 .
$$


(iii) By part (ii), we get

$$
\begin{aligned}
\left\|x_{k+1}-p\right\| & =\left\|\left(1-t_{m k}\right)\left(y_{(m-1) k}-p\right)+t_{m k}\left(T_{m}^{n_{k}} y_{(m-1) k}-p\right)\right\| \\
& \leq\left(1-t_{m k}\right)\left\|y_{(m-1) k}-p\right\|+t_{m k}\left\|T_{m}^{n_{k}} y_{(m-1) k}-p\right\| \\
& \leq\left(1-t_{m k}\right)\left\|y_{(m-1) k}-p\right\|+t_{m k}\left(1+\gamma_{k}\right)\left\|y_{(m-1) k}-p\right\| \\
& \leq\left(1+\gamma_{k}\right)\left\|y_{(m-1) k}-p\right\| \\
& \leq\left(1+\gamma_{k}\right)\left(1+\gamma_{k}\right)^{m-1}\left\|x_{k}-p\right\| \\
& \leq\left(1+\gamma_{k}\right)^{m}\left\|x_{k}-p\right\| \\
& \leq\left(1+\delta_{k}\right)\left\|x_{k}-p\right\|,
\end{aligned}
$$

where $\delta_{k}=\left(\begin{array}{c}m \\ 1\end{array}\right) \gamma_{k}+\left(\begin{array}{c}m \\ 2\end{array}\right) \gamma_{k}^{2}+\cdots+\left(\begin{array}{c}m \\ m\end{array}\right) \gamma_{k}^{m}$. Since $\sum_{k=1}^{\infty} \gamma_{k}<\infty$, then $\sum_{k=1}^{\infty} \delta_{k}<\infty$.

(iv) By part (iii), we have $\left\|x_{k+1}-p\right\| \leq\left\|x_{k}-p\right\|+\operatorname{diam}(C) \delta_{k}$ for all $k \in \mathbb{N}$. Thus, for each $l \in \mathbb{N}$,

$$
\left\|x_{k+l}-p\right\| \leq\left\|x_{k}-p\right\|+\operatorname{diam}(C) \sum_{i=k}^{k+l-1} \delta_{i} .
$$

Since $\sum_{i=1}^{\infty} \delta_{i}<\infty, \limsup _{k \rightarrow \infty} \lim \sup _{l \rightarrow \infty} \sum_{i=k}^{k+l-1} \delta_{i}=0$. The conclusion follows from Lemma 2.6 by letting $r_{k}=\left\|x_{k}-p\right\|$ and $d_{k, l}=\operatorname{diam}(C) \sum_{i=k}^{k+l-1} \delta_{i}$.

Lemma 3.2 Let $C$ be a nonempty bounded closed convex subset of a uniformly convex Banach space $X$ and $T_{1}, \ldots, T_{m} \in \mathcal{T}_{r}(C)$. Let $\left\{t_{i k}\right\}_{k=1}^{\infty} \subset[a, b] \subset(0,1)$ and $\left\{n_{k}\right\} \subset \mathbb{N}$ be such that $\left\{x_{k}\right\}$ in (9) is well defined. Assume that $F:=\bigcap_{i=1}^{m} F\left(T_{i}\right) \neq \emptyset$. Then

(i) $\lim _{k \rightarrow \infty}\left\|y_{(i-1) k}-T_{i}^{n_{k}} y_{(i-1) k}\right\|=0$, for all $i=1,2, \ldots, m$;

(ii) $\lim _{k \rightarrow \infty}\left\|x_{k}-T_{i}^{n_{k}} y_{(i-1) k}\right\|=0$, for all $i=1,2, \ldots, m$;

(iii) If the set $\mathcal{J}=\left\{k \in \mathbb{N}: n_{k+1}=1+n_{k}\right\}$ is quasi-periodic, then $\lim _{k \rightarrow \infty}\left\|x_{k}-T_{i} x_{k}\right\|=0$, for all $i=1,2, \ldots, m$.

Proof (i) Let $p \in F$, then by Lemma 3.1(iv) we have $\lim _{k \rightarrow \infty}\left\|x_{k}-p\right\|$ exists. Let

$$
\lim _{k \rightarrow \infty}\left\|x_{k}-p\right\|=c .
$$

By (10) and Lemma 3.1(ii), we get that

$$
\limsup _{k \rightarrow \infty}\left\|y_{i k}-p\right\| \leq c, \quad \text { for all } i=1, \ldots, m-1 .
$$

Note that

$$
\begin{aligned}
\left\|x_{k+1}-p\right\| & \leq\left(1-t_{m k}\right)\left\|y_{(m-1) k}-p\right\|+t_{m k}\left\|T_{m}^{n_{k}} y_{(m-1) k}-p\right\| \\
& \leq\left(1-t_{m k}\right)\left\|y_{(m-1) k}-p\right\|+t_{m k}\left(1+\gamma_{k}\right)\left\|y_{(m-1) k}-p\right\| \\
& \leq\left(1+\gamma_{k}\right)\left\|y_{(m-1) k}-p\right\| \\
& =\left(1+\gamma_{k}\right)\left\|\left(1-t_{(m-1) k}\right)\left(y_{(m-2) k}-p\right)+t_{(m-1) k}\left(T_{m-1}^{n_{k}} y_{(m-2) k}-p\right)\right\| \\
& \leq\left(1+\gamma_{k}\right)\left(\left(1-t_{(m-1) k}\right)\left\|y_{(m-2) k}-p\right\|+t_{(m-1) k}\left(1+r_{k}\right)\left\|y_{(m-2) k}-p\right\|\right) \\
& \leq\left(1+\gamma_{k}\right)^{2}\left\|y_{(m-2) k}-p\right\| \\
& \vdots \\
& \leq\left(1+\gamma_{k}\right)^{m-i}\left\|y_{i k}-p\right\|,
\end{aligned}
$$

for all $i=1, \ldots, m-1$. So that

$$
c \leq \liminf _{k \rightarrow \infty}\left\|y_{i k}-p\right\|, \quad \text { for all } i=1, \ldots, m-1 .
$$


From (11) and (12), we have

$$
\lim _{k \rightarrow \infty}\left\|y_{i k}-p\right\|=c, \quad \text { for all } i=1,2, \ldots, m-1 .
$$

That is,

$$
\lim _{k \rightarrow \infty}\left\|\left(1-t_{i k}\right)\left(y_{(i-1) k}-p\right)+t_{i k}\left(T_{i}^{n_{k}} y_{(i-1) k}-p\right)\right\|=c, \quad \text { for all } i=1,2, \ldots, m-1 .
$$

By Lemma 3.1(i) and (13), we get that

$$
\limsup _{k \rightarrow \infty}\left\|T_{i}^{n_{k}} y_{(i-1) k}-p\right\| \leq c, \quad \text { for all } j=1,2, \ldots, m-1 .
$$

By (11), (14), (15), and Lemma 2.7, we obtain

$$
\lim _{k \rightarrow \infty}\left\|y_{(i-1) k}-T_{i}^{n_{k}} y_{(i-1) k}\right\|=0, \quad \text { for all } i=1,2, \ldots, m-1 .
$$

For the case $i=m$, by Lemma 3.1(i), we have

$$
\left\|T_{m}^{n_{k}} y_{(m-1) k}-p\right\| \leq\left(1+\gamma_{k}\right)\left\|y_{(m-1) k}-p\right\| .
$$

This implies by (13) that

$$
\limsup _{k \rightarrow \infty}\left\|T_{m}^{n_{k}} y_{(m-1) k}-p\right\| \leq c .
$$

Moreover,

$$
\lim _{k \rightarrow \infty}\left\|\left(1-t_{m k}\right)\left(y_{(m-1) k}-p\right)+t_{m k}\left(T_{m}^{n_{k}} y_{(m-1) k}-p\right)\right\|=\lim _{k \rightarrow \infty}\left\|x_{k+1}-p\right\|=c .
$$

Again, by Lemma 2.7, we get that

$$
\lim _{k \rightarrow \infty}\left\|y_{(m-1) k}-T_{m}^{n_{k}} y_{(m-1) k}\right\|=0 .
$$

Thus, (16) and (18) imply that

$$
\lim _{k \rightarrow \infty}\left\|y_{(i-1) k}-T_{i}^{n_{k}} y_{(i-1) k}\right\|=0, \quad \text { for all } i=1, \ldots, m .
$$

(ii) From (9), we have

$$
\left\|y_{i k}-y_{(i-1) k}\right\|=t_{i k}\left\|T_{i}^{n_{k}} y_{(i-1) k}-y_{(i-1) k}\right\|, \quad \text { for all } i=1, \ldots, m-1 .
$$

By (19), we obtain

$$
\lim _{k \rightarrow \infty}\left\|y_{i k}-y_{(i-1) k}\right\|=0, \quad \text { for } i=1, \ldots, m-1 .
$$

From

$$
\left\|x_{k}-y_{i k}\right\| \leq\left\|x_{k}-y_{1 k}\right\|+\left\|y_{1 k}-y_{2 k}\right\|+\cdots+\left\|y_{(i-1) k}-y_{i k}\right\|, \quad \text { for all } i=1, \ldots, m-1,
$$

it follows by (20) that

$$
\lim _{k \rightarrow \infty}\left\|x_{k}-y_{i k}\right\|=0, \quad \text { for all } i=1, \ldots, m-1 .
$$

From

$$
\left\|x_{k}-T_{i}^{n_{k}} y_{(i-1) k}\right\| \leq\left\|x_{k}-y_{(i-1) k}\right\|+\left\|y_{(i-1) k}-T_{i}^{n_{k}} y_{(i-1) k}\right\|,
$$

it implies by (19) and (21) that

$$
\lim _{k \rightarrow \infty}\left\|x_{k}-T_{i}^{n_{k}} y_{(i-1) k}\right\|=0, \quad \text { for all } i=1,2, \ldots, m .
$$

(iii) For $i=1$, from (ii) we have

$$
\lim _{k \rightarrow \infty}\left\|T_{1}^{n_{k}} x_{k}-x_{k}\right\|=0 .
$$


If $i=2,3, \ldots, m$, then

$$
\begin{aligned}
\left\|T_{i}^{n_{k}} x_{k}-x_{k}\right\| & \leq\left\|T_{i}^{n_{k}} x_{k}-T_{i}^{n_{k}} y_{(i-1) k}\right\|+\left\|T_{i}^{n_{k}} y_{(i-1) k}-x_{k}\right\| \\
& \leq a_{n_{k}}\left(x_{k}\right)\left\|x_{k}-y_{(i-1) k}\right\|+\left\|T_{i}^{n_{k}} y_{(i-1) k}-x_{k}\right\| .
\end{aligned}
$$

By (21), (22), and lim $\sup _{k \rightarrow \infty} a_{n_{k}}\left(x_{k}\right)=1$, we get

$$
\limsup _{k \rightarrow \infty}\left\|T_{i}^{n_{k}} x_{k}-x_{k}\right\|=0 \quad \text { for all } i=2,3, \ldots, m \text {. }
$$

By (23) and (24), we have

$$
\lim _{k \rightarrow \infty}\left\|T_{i}^{n_{k}} x_{k}-x_{k}\right\|=0 \quad \text { for all } i=1,2, \ldots, m .
$$

From (9), we have

$$
\begin{aligned}
\left\|x_{k+1}-x_{k}\right\| & \leq\left(1-t_{m k}\right)\left\|y_{(m-1) k}-x_{k}\right\|+t_{m k}\left\|T_{m}^{n_{k}} y_{(m-1) k}-x_{k}\right\| \\
& \leq\left(1-t_{m k}\right)\left\|y_{(m-1) k}-x_{k}\right\|+t_{m k}\left(\left\|T_{m}^{n_{k}} y_{(m-1) k}-y_{(m-1) k}\right\|+\left\|y_{(m-1) k}-x_{k}\right\|\right) \\
& =\left\|y_{(m-1) k}-x_{k}\right\|+t_{m k}\left\|T_{m}^{n_{k}} y_{(m-1) k}-y_{(m-1) k}\right\| .
\end{aligned}
$$

From (19) and (21),

$$
\lim _{k \rightarrow \infty}\left\|x_{k+1}-x_{k}\right\|=0 .
$$

The proof of the remaining part is identical to the proof of [25, Lemma 4.8(iii)] upon replacing $d(\cdot, \cdot)$ with $\|\cdot\|$.

By using Lemma 3.1 and the argument in the proof of [26, Theorem 3.2], we can obtain the following result.

Lemma 3.3 Let $C$ be a nonempty bounded closed convex subset of a Banach space $X$ and $T_{1}, \ldots, T_{m} \in \mathcal{T}_{r}(C)$. Let $\left\{t_{i k}\right\}_{k=1}^{\infty} \subset[0,1]$ and $\left\{n_{k}\right\} \subset \mathbb{N}$ be such that $\left\{x_{k}\right\}$ in (9) is well defined. Assume that $F:=\bigcap_{i=1}^{m} F\left(T_{i}\right) \neq \emptyset$. Then $\left\{x_{k}\right\}$ converges strongly to a point in $F$ if and only if $\liminf _{k \rightarrow \infty} \operatorname{dist}\left(x_{k}, F\right)=0$.

Theorem 3.4 Let $X$ be a uniformly convex Banach space with the Opial property and $C$ be a nonempty bounded closed convex subset of $X$. Let $T_{1}, \ldots, T_{m} \in \mathcal{T}_{r}(C)$ be such that $F:=$ $\bigcap_{i=1}^{m} F\left(T_{i}\right) \neq \emptyset .\left\{t_{i k}\right\}_{k=1}^{\infty} \subset[a, b] \subset(0,1)$ and $\left\{n_{k}\right\} \subset \mathbb{N}$ be such that $\left\{x_{k}\right\}$ in $(9)$ is well defined. If the set $\mathcal{J}=\left\{k \in \mathbb{N}: n_{k+1}=1+n_{k}\right\}$ is quasi-periodic, then the sequence $\left\{x_{k}\right\}$ converges weakly to a common fixed point of the family $\left\{T_{i}: i=1, \ldots, m\right\}$.

Proof We have by Lemma 3.1 that $\lim _{n \rightarrow \infty}\left\|x_{k}-p\right\|$ exists for every $p \in F$. We shall prove that $\left\{x_{k}\right\}$ has a unique weak subsequential limit in $F$. For this, we suppose that there are subsequences $\left\{x_{k_{l}}\right\}$ and $\left\{x_{k_{j}}\right\}$ of $\left\{x_{k}\right\}$ which converge weakly to $u$ and $v$, respectively. By Lemma 3.2(iii), $\lim _{k \rightarrow \infty}\left\|T_{i} x_{k}-x_{k}\right\|=0$ for all $i=1, \ldots, m$. It follows from Lemma 2.9 that $u, v \in F\left(T_{i}\right)$ for all $i=1, \ldots, m$. That is $u, v \in F$. Finally, we prove that $u=v$. Suppose not, then by the Opial property we get that

$$
\begin{aligned}
\lim _{k \rightarrow \infty}\left\|x_{k}-u\right\| & =\lim _{l \rightarrow \infty}\left\|x_{k_{l}}-u\right\| \\
& <\lim _{l \rightarrow \infty}\left\|x_{k_{l}}-v\right\| \\
& =\lim _{k \rightarrow \infty}\left\|x_{k}-v\right\| \\
& =\lim _{j \rightarrow \infty}\left\|x_{k_{j}}-v\right\|
\end{aligned}
$$




$$
\begin{aligned}
& <\lim _{j \rightarrow \infty}\left\|x_{k_{j}}-u\right\| \\
& =\lim _{k \rightarrow \infty}\left\|x_{k}-u\right\| .
\end{aligned}
$$

This is a contradiction. Therefore, the proof is complete.

Theorem 3.5 Let $X$ be a uniformly convex Banach space and $C$ be a nonempty bounded closed convex subset of $X$. Let $T_{1}, \ldots, T_{m} \in \mathcal{T}_{r}(C)$ be such that $T_{i}^{l}$ is semi-compact for some $i \in\{1, \ldots, m\}$ and $l \in \mathbb{N} .\left\{t_{i k}\right\}_{k=1}^{\infty} \subset[a, b] \subset(0,1)$ and $\left\{n_{k}\right\} \subset \mathbb{N}$ be such that $\left\{x_{k}\right\}$ in (9) is well defined. Suppose that $F:=\bigcap_{i=1}^{m} F\left(T_{i}\right) \neq \emptyset$ and the set $\mathcal{J}=\left\{k \in \mathbb{N}: n_{k+1}=1+n_{k}\right\}$ is quasi-periodic. Then $\left\{x_{k}\right\}$ converges strongly to a common fixed point of the family $\left\{T_{i}: i=\right.$ $1,2, \ldots, m\}$.

Proof By Lemma 3.2, we have

$$
\lim _{k \rightarrow \infty}\left\|x_{k}-T_{i} x_{k}\right\|=0, \quad \text { for all } i=1, \ldots, m .
$$

Let $i \in\{1, \ldots, m\}$ be such that $T_{i}^{l}$ is semi-compact. Thus, by Lemma 2.8,

$$
\lim _{k \rightarrow \infty}\left\|x_{k}-T_{i}^{l} x_{k}\right\|=0 .
$$

We can also find a subsequence $\left\{x_{n_{j}}\right\}$ of $\left\{x_{k}\right\}$ such that $\lim _{j \rightarrow \infty} x_{k_{j}}=q \in C$. Hence, from (27), we have

$$
\left\|q-T_{i} q\right\|=\lim _{j \rightarrow \infty}\left\|x_{k_{j}}-T_{i} x_{k_{j}}\right\|=0, \quad \text { for all } i=1, \ldots, m .
$$

Thus $q \in F$. Therefore, $\left\{x_{k_{j}}\right\}$ converges strongly to $q \in F$. But since $\lim _{k \rightarrow \infty}\left\|x_{k}-q\right\|$ exists, $\left\{x_{k}\right\}$ must itself converges to $q$. This completes the proof.

Theorem 3.6 Let $X$ be a uniformly convex Banach space and $C$ be a nonempty bounded closed convex subset of $X$. Let $\left\{T_{1}, \ldots, T_{m}\right\} \subset \mathcal{T}_{r}(C)$ be satisfy Condition $\left(A^{\prime \prime}\right)$. Let $\left\{t_{i k}\right\}_{k=1}^{\infty} \subset$ $[a, b] \subset(0,1)$ and $\left\{n_{k}\right\} \subset \mathbb{N}$ be such that $\left\{x_{k}\right\}$ in (9) is well defined. Suppose that $F:=$ $\bigcap_{i=1}^{m} F\left(T_{i}\right) \neq \emptyset$ and the set $\mathcal{J}=\left\{k \in \mathbb{N}: n_{k+1}=1+n_{k}\right\}$ is quasi-periodic. Then $\left\{x_{k}\right\}$ converges strongly to a common fixed point of the family $\left\{T_{i}: i=1,2, \ldots, m\right\}$.

Proof By Lemma 3.2, $\lim _{k \rightarrow \infty}\left\|x_{k}-T_{i} x_{k}\right\|=0$, for all $i=1,2, \ldots, m$. By using Condition $\left(A^{\prime \prime}\right)$, there exists a nondecreasing function $f:[0, \infty) \rightarrow[0, \infty)$ with $f(0)=0, f(r)>0$ for $r \in$ $(0, \infty)$ such that

$$
\lim _{k \rightarrow \infty} f\left(\operatorname{dist}\left(x_{k}, F\right)\right) \leq \lim _{k \rightarrow \infty}\left\|x_{k}-T_{j} x_{k}\right\|=0 \quad \text { for some } j=1, \ldots, m .
$$

This implies that $\lim _{k \rightarrow \infty} \operatorname{dist}\left(x_{k}, F\right)=0$. The conclusion follows from Lemma 3.3.

\subsection{Results for unbounded domains}

To relax the boundedness of the domains we have to add some condition on the sequence $\left\{b_{n_{k}}\right\}$.

Lemma 3.7 Let $C$ be a nonempty closed convex subset of a Banach space $X$ and $T_{1}, \ldots, T_{m} \in$ $\mathcal{T}_{r}(C)$ be such that $F:=\bigcap_{i=1}^{m} F\left(T_{i}\right) \neq \emptyset$. Let $\left\{t_{i k}\right\}_{k=1}^{\infty} \subset[0,1]$ and $\left\{n_{k}\right\} \subset \mathbb{N}$ be such that $\left\{x_{k}\right\}$ in (9) is well defined. Assume that $\sum_{k=1}^{\infty} \sup _{x \in C} b_{n_{k}}(x)<\infty$. Then for $p \in F$, we have $\lim _{k \rightarrow \infty}\left\|x_{k}-p\right\|$ exists. 
Proof Similar to the proof of Lemma 3.1, we can show that $\left\|x_{k+1}-p\right\| \leq\left(1+\eta_{k}\right)\left\|x_{k}-p\right\|$ for all $k \in \mathbb{N}$, where $\eta_{k}=\left(\begin{array}{c}m \\ 1\end{array}\right) s_{k}+\left(\begin{array}{c}m \\ 2\end{array}\right) s_{k}^{2}+\cdots+\left(\begin{array}{c}m \\ m\end{array}\right) s_{k}^{m}$ and $s_{k}=\sup _{x \in C} b_{n_{k}}(x)$. By assumption, we have $\sum_{k=1}^{\infty} s_{k}^{i}<\infty$ for all $i=1, \ldots, m$. It follows that $\sum_{k=1}^{\infty} \eta_{k}<\infty$. By Lemma 2.5, we get that $\lim _{k \rightarrow \infty}\left\|x_{k}-p\right\|$ exists.

By using Lemma 3.7 and the argument in Section 3.1 we can obtain the following results.

Lemma 3.8 Let C be a nonempty closed convex subset of a Banach space $X$ and $T_{1}, \ldots, T_{m} \in$ $\mathcal{T}_{r}(C)$ be such that $F:=\bigcap_{i=1}^{m} F\left(T_{i}\right) \neq \emptyset$. Let $\left\{t_{i k}\right\}_{k=1}^{\infty} \subset[0,1]$ and $\left\{n_{k}\right\} \subset \mathbb{N}$ be such that $\left\{x_{k}\right\}$ in (9) is well defined. Assume that $\sum_{k=1}^{\infty} \sup _{x \in C} b_{n_{k}}(x)<\infty$. Then

(i) $\lim _{k \rightarrow \infty}\left\|y_{(i-1) k}-T_{i}^{n_{k}} y_{(i-1) k}\right\|=0$, for all $i=1,2, \ldots, m$;

(ii) $\lim _{k \rightarrow \infty}\left\|x_{k}-T_{i}^{n_{k}} y_{(i-1) k}\right\|=0$, for all $i=1,2, \ldots, m$;

(iii) If the set $\mathcal{J}=\left\{k \in \mathbb{N}: n_{k+1}=1+n_{k}\right\}$ is quasi-periodic, then $\lim _{k \rightarrow \infty}\left\|x_{k}-T_{i} x_{k}\right\|=0$, for all $i=1,2, \ldots, m$.

Lemma 3.9 Let $C$ be a nonempty closed convex subset of a Banach space $X$ and $T_{1}, \ldots, T_{m} \in$ $\mathcal{T}_{r}(C)$ be such that $F:=\bigcap_{i=1}^{m} F\left(T_{i}\right) \neq \emptyset$. Let $\left\{t_{i k}\right\}_{k=1}^{\infty} \subset[0,1]$ and $\left\{n_{k}\right\} \subset \mathbb{N}$ be such that $\left\{x_{k}\right\}$ in (9) is well defined. Assume that $\sum_{k=1}^{\infty} \sup _{x \in C} b_{n_{k}}(x)<\infty$. Then $\left\{x_{k}\right\}$ converges strongly to a point in $F$ if and only if $\liminf _{k \rightarrow \infty} \operatorname{dist}\left(x_{k}, F\right)=0$.

Theorem 3.10 Let $X$ be a uniformly convex Banach space with the Opial property and $C$ be a nonempty closed convex subset of $X$. Let $T_{1}, \ldots, T_{m} \in \mathcal{T}_{r}(C)$ be such that $F:=$ $\bigcap_{i=1}^{m} F\left(T_{i}\right) \neq \emptyset .\left\{t_{i k}\right\}_{k=1}^{\infty} \subset[a, b] \subset(0,1)$ and $\left\{n_{k}\right\} \subset \mathbb{N}$ be such that $\left\{x_{k}\right\}$ in (9) is well defined. Assume that $\sum_{k=1}^{\infty} \sup _{x \in C} b_{n_{k}}(x)<\infty$ and the set $\mathcal{J}=\left\{k \in \mathbb{N}: n_{k+1}=1+n_{k}\right\}$ is quasiperiodic. Then the sequence $\left\{x_{k}\right\}$ converges weakly to a common fixed point of the family $\left\{T_{i}: i=1, \ldots, m\right\}$.

Theorem 3.11 Let $X$ be a uniformly convex Banach space and $C$ be a nonempty closed convex subset of $X$. Let $T_{1}, \ldots, T_{m} \in \mathcal{T}_{r}(C)$ be such that $T_{i}^{l}$ is semi-compact for some $i \in$ $\{1, \ldots, m\}$ and $l \in \mathbb{N},\left\{t_{i k}\right\}_{k=1}^{\infty} \subset[a, b] \subset(0,1)$ and $\left\{n_{k}\right\} \subset \mathbb{N}$ be such that $\left\{x_{k}\right\}$ in (9) is well defined. Suppose that $\sum_{k=1}^{\infty} \sup _{x \in C} b_{n_{k}}(x)<\infty, F:=\bigcap_{i=1}^{m} F\left(T_{i}\right) \neq \emptyset$ and the set $\mathcal{J}=\{k \in \mathbb{N}$ : $\left.n_{k+1}=1+n_{k}\right\}$ is quasi-periodic. Then $\left\{x_{k}\right\}$ converges strongly to a common fixed point of the family $\left\{T_{i}: i=1,2, \ldots, m\right\}$.

Theorem 3.12 Let $X$ be a uniformly convex Banach space and $C$ be a nonempty closed convex subset of $X$. Let $\left\{T_{1}, \ldots, T_{m}\right\} \subset \mathcal{T}_{r}(C)$ be satisfy Condition $\left(A^{\prime \prime}\right)$. Let $\left\{t_{i k}\right\}_{k=1}^{\infty} \subset[a, b] \subset$ $(0,1)$ and $\left\{n_{k}\right\} \subset \mathbb{N}$ be such that $\left\{x_{k}\right\}$ in (9) is well defined. Suppose that $\sum_{k=1}^{\infty} \sup _{x \in C} b_{n_{k}}(x)<$ $\infty, F:=\bigcap_{i=1}^{m} F\left(T_{i}\right) \neq \emptyset$ and the set $\mathcal{J}=\left\{k \in \mathbb{N}: n_{k+1}=1+n_{k}\right\}$ is quasi-periodic. Then $\left\{x_{k}\right\}$ converges strongly to a common fixed point of the family $\left\{T_{i}: i=1,2, \ldots, m\right\}$.

\section{Results in CAT(0) spaces}

A metric space $X$ is a $\operatorname{CAT}(0)$ space if it is geodesically connected, and if every geodesic triangle in $X$ is at least as thin as its comparison triangle in the Euclidean plane. It is well known that any complete, simply connected Riemannian manifold having nonpositive sectional curvature is a CAT(0) space. Other examples include Pre-Hilbert spaces (see [32]), $\mathbb{R}$-trees (see [33]), Euclidean buildings (see [34]), the complex Hilbert ball with a hyperbolic metric (see [35]), and many others. For a thorough discussion of these spaces and of 
the fundamental role they play in geometry, we refer the reader to Bridson and Haefliger [32].

Let $x, y \in X$, by Lemma 2.1(iv) of [36] for each $t \in[0,1]$, there exists a unique point $z \in$ $[x, y]$ such that

$$
d(x, z)=t d(x, y) \quad \text { and } \quad d(y, z)=(1-t) d(x, y) .
$$

From now on, we will use the notation $(1-t) x \oplus t y$ for the unique point $z$ satisfying (28).

Let $\left\{x_{n}\right\}$ be a bounded sequence in a metric space $(X, d)$. For $x \in X$, we set

$$
r\left(x,\left\{x_{n}\right\}\right)=\limsup _{n \rightarrow \infty} d\left(x, x_{n}\right) .
$$

The asymptotic radius $r\left(\left\{x_{n}\right\}\right)$ of $\left\{x_{n}\right\}$ is given by

$$
r\left(\left\{x_{n}\right\}\right)=\inf \left\{r\left(x,\left\{x_{n}\right\}\right): x \in X\right\},
$$

and the asymptotic center $A\left(\left\{x_{n}\right\}\right)$ of $\left\{x_{n}\right\}$ is the set

$$
A\left(\left\{x_{n}\right\}\right)=\left\{x \in X: r\left(x,\left\{x_{n}\right\}\right)=r\left(\left\{x_{n}\right\}\right)\right\} .
$$

It is known from Proposition 7 of [37] that in a CAT(0) space, $A\left(\left\{x_{n}\right\}\right)$ consists of exactly one point. We now give the definition of $\Delta$-convergence.

Definition 4.1 $[38,39]$ A sequence $\left\{x_{n}\right\}$ in a metric space $X$ is said to $\Delta$-converge to $x \in X$ if $x$ is the unique asymptotic center of $\left\{u_{n}\right\}$ for every subsequence $\left\{u_{n}\right\}$ of $\left\{x_{n}\right\}$. In this case we write $\Delta-\lim _{n} x_{n}=x$ and call $x$ the $\Delta$-limit of $\left\{x_{n}\right\}$.

Let $C$ be a nonempty closed convex subset of a CAT(0) space $X$ and fix $x_{1} \in C$. Define a sequence $\left\{x_{k}\right\}$ in $C$ as

$$
\begin{aligned}
& x_{k+1}=\left(1-t_{m k}\right) y_{(m-1) k} \oplus t_{m k} T_{m}^{n_{k}} y_{(m-1) k}, \\
& y_{(m-1) k}=\left(1-t_{(m-1) k}\right) y_{(m-2) k} \oplus t_{(m-1) k} T_{m-1}^{n_{k}} y_{(m-2) k}, \\
& y_{(m-2) k}=\left(1-t_{(m-2) k}\right) y_{(m-3) k} \oplus t_{(m-2) k} T_{m-2}^{n_{k}} y_{(m-3) k}, \\
& \vdots \\
& y_{2 k}=\left(1-t_{2 k}\right) y_{1 k} \oplus t_{2 k} T_{2}^{n_{k}} y_{1 k}, \\
& y_{1 k}=\left(1-t_{1 k}\right) y_{0 k} \oplus t_{1 k} T_{1}^{n_{k}} y_{0 k}, \\
& y_{0 k}=x_{k}, \quad k \in \mathbb{N},
\end{aligned}
$$

where $T_{1}, \ldots, T_{m} \in \mathcal{T}(C),\left\{t_{i k}\right\}_{k=1}^{\infty}$ are sequences in $[0,1]$ for all $i=1,2, \ldots, m$, and $\left\{n_{k}\right\}$ be an increasing sequence of natural numbers.

By using the argument in Section 3 together with the results in [25, 36, 40, 41], we can also obtain the analogous results for $\mathrm{CAT}(0)$ spaces.

Theorem 4.2 Let $C$ be a nonempty closed convex subset of a complete CAT(0) space $X$. Let $T_{1}, \ldots, T_{m} \in \mathcal{T}_{r}(C)$ be such that $F:=\bigcap_{i=1}^{m} F\left(T_{i}\right) \neq \emptyset,\left\{t_{i k}\right\}_{k=1}^{\infty} \subset[a, b] \subset(0,1)$ and $\left\{n_{k}\right\} \subset \mathbb{N}$ be such that $\left\{x_{k}\right\}$ in (29) is well defined. Suppose that either $C$ is bounded or $\sum_{k=1}^{\infty} \sup _{x \in C} b_{n_{k}}(x)<\infty$. If the set $\mathcal{J}=\left\{k \in \mathbb{N}: n_{k+1}=1+n_{k}\right\}$ is quasi-periodic, then the sequence $\left\{x_{k}\right\} \Delta$-converges to a common fixed point of the family $\left\{T_{i}: i=1, \ldots, m\right\}$.

Theorem 4.3 Let $C$ be a nonempty closed convex subset of a complete CAT(0) space $X$. Let $T_{1}, \ldots, T_{m} \in \mathcal{T}_{r}(C)$ be such that $F:=\bigcap_{i=1}^{m} F\left(T_{i}\right) \neq \emptyset$ and $T_{i}^{l}$ is semi-compact for some 
$i \in\{1, \ldots, m\}$ and $l \in \mathbb{N}$. Let $\left\{t_{i k}\right\}_{k=1}^{\infty} \subset[a, b] \subset(0,1)$ and $\left\{n_{k}\right\} \subset \mathbb{N}$ be such that $\left\{x_{k}\right\}$ in (29) is well defined. Suppose that either $C$ is bounded or $\sum_{k=1}^{\infty} \sup _{x \in C} b_{n_{k}}(x)<\infty$. If the set $\mathcal{J}=$ $\left\{k \in \mathbb{N}: n_{k+1}=1+n_{k}\right\}$ is quasi-periodic, then $\left\{x_{k}\right\}$ converges strongly to a common fixed point of the family $\left\{T_{i}: i=1,2, \ldots, m\right\}$.

Theorem 4.4 Let $C$ be a nonempty closed convex subset of a complete $C A T(0)$ space $X$. Let $\left\{T_{1}, \ldots, T_{m}\right\} \subset \mathcal{T}_{r}(C)$ be satisfy Condition $\left(A^{\prime \prime}\right)$ and $F:=\bigcap_{i=1}^{m} F\left(T_{i}\right) \neq \emptyset$. Let $\left\{t_{i k}\right\}_{k=1}^{\infty} \subset$ $[a, b] \subset(0,1)$ and $\left\{n_{k}\right\} \subset \mathbb{N}$ be such that $\left\{x_{k}\right\}$ in (29) is well defined. Suppose that either $C$ is bounded or $\sum_{k=1}^{\infty} \sup _{x \in C} b_{n_{k}}(x)<\infty$. If the set $\mathcal{J}=\left\{k \in \mathbb{N}: n_{k+1}=1+n_{k}\right\}$ is quasi-periodic, then $\left\{x_{k}\right\}$ converges strongly to a common fixed point of the family $\left\{T_{i}: i=1,2, \ldots, m\right\}$.

Competing interests

The authors declare that they have no competing interests.

\section{Authors' contributions}

Both the authors contributed equally and significantly in writing this paper. All authors read and approved the final manuscript.

\section{Acknowledgements}

This article is dedicated to Professor Anthony To-Ming Lau for celebrating his great achievements in the development of fixed point theory and applications. It was supported by the Centre of Excellence in Mathematics, the Commission on Higher Education, Thailand. Bancha Nanjaras also thanks the Graduate School of Chiang Mai University, Thailand.

Received: 17 March 2012 Accepted: 20 June 2012 Published: 2 July 2012

\section{References}

1. Lau, AT: Approximation of fixed points for amenable semigroups of nonexpansive mappings and strongly regular nets. In: Nonlinear Analysis and Convex Analysis, pp. 179-188. Yokohama Publisher, Yokohama (2010)

2. Lau, AT: Compactifications and fixed point properties. Fixed Point Theory Appl. 5, 53-58 (2004)

3. Lau, AT: Normal structure and common fixed point properties for semigroups of nonexpansive mappings in Banach spaces. Fixed Point Theory Appl. 2010, Article ID 580956 (2010)

4. Lau, AT: Weak* fixed point property for dual Banach spaces associated to locally compact groups. Nonlinear Analysis Convex Analysis (Japanese). Kyoto, Japan (2000)

5. Lau, AT, Leinert, M: Fixed point property and the Fourier algebra of a locally compact group. Trans. Am. Math. Soc 360, 6389-6402 (2008)

6. Lau, AT, Mah, PF: Fixed point property for Banach algebras associated to locally compact groups. J. Funct. Anal. 258, 357-372 (2010)

7. Lau, AT, Mah, PF, Ülger, A: Fixed point property and normal structure for Banach spaces associated to locally compact groups. Proc. Am. Math. Soc. 125, 2021-2027 (1997)

8. Lau, AT, Miyake, H, Takahashi, W: Approximation of fixed points for amenable semigroups of nonexpansive mappings in Banach spaces. Nonlinear Anal. 67, 1211-1225 (2007)

9. Lau, AT, Takahashi, W: Fixed point and non-linear ergodic theorems for semigroups of nonlinear mappings. In: Handbook of Metric Fixed Point Theory, pp. 517-555. Kluwer Academic, Dordrecht (2001)

10. Lau, AT, Takahashi, W: Fixed point properties for semigroup of nonexpansive mappings on Fréchet spaces. Nonlinear Anal. 70, 3837-3841 (2009)

11. Lau, AT, Zhang, Y: Fixed point properties of semigroups of non-expansive mappings. J. Funct. Anal. 254, 2534-2554 (2008)

12. Browder, FE: Nonexpansive nonlinear operators in a Banach space. Proc. Natl. Acad. Sci. USA 54, 1041-1044 (1965)

13. Göhde, D: Zum Prinzip der Kontraktiven Abbildung. Math. Nachr. 30, 251-258 (1965)

14. Kirk, WA: A fixed point theorem for mappings which do not increase distance. Am. Math. Mon. 72, 1004-1006 (1965)

15. Ishikawa, S: Fixed points by a new iteration method. Proc. Am. Math. Soc. 44, 147-150 (1974)

16. Rhoades, BE: Comments on two fixed point iteration methods. J. Math. Anal. Appl. 56, 741-750 (1976)

17. Franks, RL, Marzec, RP: A theorem on mean value iterations. Proc. Am. Math. Soc. 30, 324-326 (1971)

18. Tan, KK, Xu, HK: Approximating fixed points of nonexpansive mappings by the Ishikawa iteration process. J. Math. Anal. Appl. 178, 301-308 (1993)

19. Ghosh, MK, Debnath, L: Convergence of Ishikawa iterates of quasi-nonexpansive mappings. J. Math. Anal. Appl. 207, 96-103 (1997)

20. Chidume, CE, Mutangadura, SA: An example of the Mann iteration method for Lipschitz pseudocontractions. Proc. Am. Math. Soc. 129, 2359-2363 (2001)

21. Chidume, CE, Shahzad, N: Strong convergence of an implicit iteration process for a finite family of nonexpansive mappings. Nonlinear Anal. 62, 1149-1156 (2005)

22. Goebel, K, Kirk, WA: A fixed point theorem for asymptotically nonexpansive mappings. Proc. Am. Math. Soc. 35 , 171-174 (1972)

23. Kirk, WA, Xu, HK: Asymptotic pointwise contractions. Nonlinear Anal. 69, 4706-4712 (2008) 
24. Kozlowski, WM: Fixed point iteration processes for asymptotic pointwise nonexpansive mappings in Banach spaces. J. Math. Anal. Appl. 377, 43-52 (2011)

25. Pasom, $P$, Panyanak, B: Common fixed points for asymptotic pointwise nonexpansive mappings in metric and Banach spaces. J. Appl. Math. 2012, Article ID 327434 (2012)

26. Kettapun, A, Kananthai, A, Suantai, S: A new approximation method for common fixed points of a finite family of asymptotically quasi-nonexpansive mappings in Banach spaces. Comput. Math. Appl. 60, 1430-1439 (2010)

27. Pasom, P, Panyanak, B: Common fixed points for asymptotic pointwise nonexpansive mappings. Fixed Point Theory (in press)

28. Sun, Z-H: Strong convergence of an implicit iteration process for a finite family of asymptotically quasi-nonexpansive mappings. J. Math. Anal. Appl. 286, 351-358 (2003)

29. Bruck, RE, Kuczumow, T, Reich, S: Convergence of iterates of asymptotically nonexpansive mappings in Banach spaces with the uniform Opial property. Collect. Math. 65, 169-179 (1993)

30. Schu, J: Weak and strong convergence to fixed points of asymptotically nonexpansive mappings. Bull. Aust. Math Soc. 43, 153-159 (1991)

31. Zeidler, E: Nonlinear Functional Analysis and Its Applications I, Fixed Points Theorems. Springer, New York (1986)

32. Bridson, M, Haefliger, A: Metric Spaces of Non-Positive Curvature. Springer, Berlin (1999)

33. Kirk, WA: Fixed point theorems in CAT(0) spaces and $\mathbb{R}$-trees. Fixed Point Theory Appl. 2004, 309-316 (2004)

34. Brown, KS: Buildings. Springer, New York (1989)

35. Goebel, K, Reich, S: Uniform Convexity, Hyperbolic Geometry, and Nonexpansive Mappings. Dekker, New York (1984)

36. Dhompongsa, S, Panyanak, B: On $\Delta$-convergence theorems in CAT(0) spaces. Comput. Math. Appl. 56, 2572-2579 (2008)

37. Dhompongsa, S, Kirk, WA, Sims, B: Fixed points of uniformly Lipschitzian mappings. Nonlinear Anal. 65, 762-772 (2006)

38. Lim, TC: Remarks on some fixed point theorems. Proc. Am. Math. Soc. 60, 179-182 (1976)

39. Kirk, WA, Panyanak, B: A concept of convergence in geodesic spaces. Nonlinear Anal. 68, 3689-3696 (2008)

40. Hussain, N, Khamsi, MA: On asymptotic pointwise contractions in metric spaces. Nonlinear Anal. 71, 4423-4429 (2009)

41. Khamsi, MA, Khan, AR: Inequalities in metric spaces with applications. Nonlinear Anal. 74, 4036-4045 (2011)

doi:10.1186/1687-1812-2012-108

Cite this article as: Nanjaras and Panyanak: An approximation method for common fixed points of a finite family of asymptotic pointwise nonexpansive mappings. Fixed Point Theory and Applications 2012 2012:108.

\section{Submit your manuscript to a SpringerOpen ${ }^{\ominus}$ journal and benefit from:}

- Convenient online submission

Rigorous peer review

- Immediate publication on acceptance

- Open access: articles freely available online

- High visibility within the field

- Retaining the copyright to your article 